ledge is often one of the basic requirements when assessing quality of care.

It has been claimed that the purchaser-provider split in the health system provides more choice for patients and doctors. ${ }^{2}$ For this new found freedom to be translated into improved care, those bodies responsible for buying services on behalf of patients must be large enough to have at their disposal sufficient information to make the best choice among competing provider units. The resources required for this would normally be available only to relatively large scale commissioning bodies such as health authorities or commissioning consortiums. Unfortunately, Potamitis and colleagues do not say how many of the general practitioners who responded in their study were fundholders or had been involved in commissioning ophthalmic services.

Modern techniques do not necessarily equate with improved quality of care. C M S Royston and colleagues reported that in laparoscopic surgery morbidity figures improve only when training and assessment are adequate. ${ }^{3}$ Is there not a danger that units will, in an attempt to attract potential purchasers, adopt new practices before they have been adequately evaluated? We may be left with the situation where internal market forces have allowed surgical innovation to be led from a position of relative ignorance.

MARK DAVIES General practitioner JANE LOGAN General practitioner JENNIFER LAW General practitioner

Mawbey Brough Health Centre, London SW8 2UD

1 Potamitis T, Fouladi M, Aggarwal RK, Jones HS, Frelder AR. General practitioners' awareness of different techniques of cataract surgery: implications for quality of care. $B M 71994$; 308:1334-5. (21 May.)

2 Secretary of State for Health. The health of the nation. London: HMSO, 1991

3 Royston CMS, Landsdown MRJ, Brough WA. Teaching laparoscopic surgery: the need for guidelines. BMF 1994;308:1023-5. (16 April.)

\section{Integrated care for diabetes}

EdITOR,-The Diabetes Integrated Care Evaluation Team reports a comparison of integrated care versus conventional care for diabetes. ${ }^{1}$ In our opinion the results of this study cannot be generalised to all diabetic patients, even if the exclusion criteria are taken into account. The mean glycated haemoglobin concentration when the patients were recruited is impressive, being nearly normal $(5.3 \%$ (SD 1.4\%); normal <5.3\%); it is evidence of good metabolic control before the trial. In the diabetes control and complications trial the mean glycated haemoglobin concentration at recruitment varied from $8.8 \%(1.6 \%)$ to $9.0 \%(1.5 \%)$ (normal value $5.05 \%(0.5 \%){ }^{2}$ After two years the value in the intensive therapy group had fallen to about $7 \%$, thus remaining clearly above normal.

The degree of glycaemic control among noninsulin dependent patients who receive conventional care is not well known. The United Kingdom prospective diabetes study should answer this question next year. Nevertheless, in that study the median glycated haemoglobin concentration over three years varied from $6.2 \%$ to $7 \cdot 2 \%,{ }^{3}$ with exclusion criteria at recruitment similar to those of the diabetes integrated care evaluation study. In France, Guillausseau et al reported a mean glycated haemoglobin concentration of $8.4 \%(1.9 \%)$ in 246 non-insulin dependent patients and of $9.3 \%(1.9 \%)$ in 125 insulin dependent patients attending a diabetic clinic (normal value $6 \cdot 2 \%(0 \cdot 7 \%){ }^{4}$ We would therefore be interested to know the training programme of the traditional hospital clinic model in the Aberdeen Health Centre. We think that the statement that "the model of integrated care for diabetes is at least as effective as conventional hospital clinic care" applies only to diabetic patients with good metabolic control.

P CHEDIN

Medical practitioner

J CAHEN-VARSAUX Chief doctor

Department of Diabetology

Hopital Victor Dupouy,

95107 Argenteuil Cedex,

France

1 Diabetes Integrated Care Evaluation Team. Integrated care for diabetes: clinical, psychosocial, and economic evaluation BMF 1994;308:1208-12. (7 May.)

2 Diabetes Control and Complications Trial Research Group. The effect of intensive treatment of diabetes on the developmen and progression of long-term complications in insulindependent diabetes mellitus. N Engl f Med 1993;329:977-86.

3 United Kingdom Prospective Diabetes Study. VIII. Study desion, progress and performance. Diabetologia 1991:34 $: 877-90$

4 Guillausseau PJ, Charles MA, Godard V, Timsit J, Chanson P, Paolaggi $F$, et al. Comparison of fructosamine with glycated hemoglobin as an index of glycemic control in diabetic patients. Diabetes Res 1990;13:127-31.

\section{Chronic fatigue syndrome and myalgic encephalomyelitis}

Edror,-Our recent editorial on the chronic fatigue syndrome and myalgic encephalomyelitis prompted considerable correspondence, ${ }^{1}$ which raised issues of case definition, clinical management, and attitudes towards people with psychiatric illnesses. Sadly, many of our critics show that the editor of the $B M 7$ is wrong to state in the "editor's choice" in the issue of 14 May that "only the naivest medical students think that diseases have some independent, objective reality." Medical students show greater intellectual sophistication in tackling the classification of ill defined illnesses than many patients and doctors-and particularly medical practitioners with self diagnosed myalgic encephalomyelitis.'

Case definition-Ellen M Goudsmit ${ }^{1}$ and Nick Anderson $^{1}$ assert that research criteria for the chronic fatigue syndrome fail to distinguish myalgic encephalomyelitis and exaggerate psychiatric associations. The best replicated research finding, however, is that patients suffer substantial emotional morbidity, whether the chronic fatigue syndrome is defined by British or, as patient groups prefer, Australian or American criteria. ${ }^{2}$ All three sets of criteria can be used to identify cases on a continuum of fatigue, ${ }^{3}$ which includes myalgic encephalomyelitis. We did not cite D O Ho-Yen's prevalence study as it used an idiosyncratic definition of cases of the chronic fatigue syndrome and surveyed doctors' diagnoses rather than patients.

Management-Patients' self help groups can have valuable informative and supportive functions. In stating that we implied that this was not so, Ho-Yen and Grant fail to differentiate between self help and self help groups and between treatment and support. ${ }^{1}$ We referred to attributional style and its prognostic implications for individual patients; overemphasis of a viral aetiology may promote demoralisation and avoidance of activity and thus contribute to a poor outcome. We are encouraged that the patients' organisations now advocate a gradual increase in activity and provide more optimistic outlooks with regard to outcome than they once did. ${ }^{1}$ The prognosis seems to be better still for treated patients with the chronic fatigue syndrome or myalgic encephalomyelitis: $70 \%$ of longstanding cases improved with cognitivebehavioural treatment and with antidepressants as required, compared with $20 \%$ of patients who refused such treatment.

Attitudes-Clare Fleming claims that we concentrated on psychological slants rather than taking a holistic view.' All specialists need to beware of conceptualising illness in models most familiar to themselves; but the association between the chronic fatigue syndrome or myalgic encephalomyelitis and psychiatric or psychological problems is indisputable, ${ }^{2}$ even though the conditions are not entirely explicable in these terms. Karen Prince states that "what is really at issue is whether this illness is real or imaginary." Such dualistic attitudes to physical and mental illness from members of the medical profession, and particularly from members of the profession who suffer from the chronic fatigue syndrome or myalgic encephalomyelitis, make it all the more understandable that patients balk at suggestions that psychiatric and psychological factors are relevant. The repeated criticism of our editorial and the scientific medical journals-that they are biased towards psychiatric and away from "organic" aetiological theories-is based on isolated reports of results of brain imaging and neuroendocrine findings, which have not been replicated and have not controlled for depression and inactivity. These comments typify stereotyped views of psychiatric illnesses as not real, unrelated to cerebral disorder, and therefore the sufferers' fault-none of which is true.

Accusations of bias arise from a misunderstanding of the nature of progress in medical research. Replicated, peer reviewed findings ensure that doctors and well informed patients are not misled by preliminary reports of research or exaggerated claims in the media, examples of which are numerous concerning the chronic fatigue syndrome and myalgic encephalomyelitis. Constructive debate with the patients' organisations, based on scientific evidence, is part of the process of improving the treatment and outlook for sufferers. Doctors must learn from their patients' experiences, but the myalgic encephalomyelitis societies should not try to set the research agenda or shout down views with which they disagree. The editors of medical journals could equally be accused of bias towards the self appointed patients' representatives in printing their simplistic criticism of evolving knowledge in these complex conditions.

S M LAWRIE

Department of Psychiatry,

Royal Edinburgh Hospital

Edinburgh EH10 5HF

Lecturer

airmyres Hospital

A PELOSI

East Kilbride, Glasgow G75 8RG

1 Correspondence. BMF 1994;308:1297-301. (14 May.)

2 David AS. Postviral fatigue syndrome and psychiatry. $\mathrm{Br} \mathrm{Med}$ Bull 1991;46:966-88.

3 Bates DW, Schmitt W, Buchwald D, Ware NC, Lee J, Thoyer E, et al. Prevalence of fatigue and chronic fatigue in a primary care practice. Arch Intern Med 1993;153:2759-65.

4 Bonner D, Ron M, Chalder T, Butler S, Wessely S. Chronic fatigue syndrome: a follow-up study. $f$ Neurol Neurosurg Psychiatry 1994;57:617-21.

\section{Alcohol and blood pressure}

EDITOR,-The INTERSALT group addressed the relation between alcohol intake and blood pressure and advocates a reduction in population mean alcohol intake. It concludes, "Overall, the data indicate the usefulness of an approach targeting those at high risk as well as the general population to reduce the adverse effects of alcohol on blood pressure." The group also states that a reduction in systolic blood pressure of $5 \mathrm{~mm} \mathrm{Hg}$ achieved by "favourable lifestyle changes" would reduce coronary mortality by $9 \%$. Although agreeing with this statement in general, I doubt whether it applies to reductions in pressure achieved by limiting alcohol consumption.

Men who are light to moderate drinkers (consuming 1-299 $\mathrm{ml} /$ week) may reduce their blood pressure by $1 \mathrm{~mm} \mathrm{Hg}$ by stopping drinking, but epidemiological evidence suggests that their coronary mortality may increase by up to $10 \%{ }^{2}$ 